\title{
Chasing a Paper Tiger: Evaluating Buffalo’s Analysis of Impediments to Fair Housing Choice
}

\author{
Robert Mark Silverman ${ }^{1}$, Kelly L. Patterson ${ }^{2}$, Jade Lewis ${ }^{1}$ \\ ${ }^{1}$ Department of Urban and Regional Planning, University at Buffalo, Buffalo, USA \\ ${ }^{2}$ School of Social Work, University at Buffalo, Buffalo, USA \\ Email: rms35@buffalo.edu
}

Received June $3^{\text {rd }}$, 2013; revised July $3^{\text {rd }}$, 2013; accepted July $10^{\text {th }}$, 2013

\begin{abstract}
Copyright (C) 2013 Robert Mark Silverman et al. This is an open access article distributed under the Creative Commons Attribution License, which permits unrestricted use, distribution, and reproduction in any medium, provided the original work is properly cited.
\end{abstract}

\begin{abstract}
This article focuses on a specific component of the US Department of Housing and Urban Development's (HUD's) strategy to implement fair housing policy, its requirement for local jurisdictions that receive community development block grant (CDBG) dollars to prepare an analysis of impediments to fair housing choice (AI) report. The article's analysis is based on an evaluation of the City of Buffalo's 2004 AI report. The evaluation was conducted by a local fair housing organization in collaboration with university-based researchers. The findings from the evaluation revealed that the City had made little progress in implementing the action plan from its AI report over an eight year period. This was an outgrowth of local funding constraints, limited staff capacity, ambiguous HUD rules for AI reporting, and a lack of political will to pursue fair housing in Buffalo. In light of these findings, we recommend that HUD: mandate timeframes for AI implementation, require AI updates at regular intervals, and more clearly specify the format and content of AI reports. We also recommend that HUD require jurisdictions to include evaluation plans in their AI reports and measure outcomes from the implementation of AI action plans. These reforms will enhance the ability of AI reports to serve as effective planning tools for the affirmative furthering of fair housing policy.
\end{abstract}

Keywords: Fair Housing; Discrimination; Evaluation; Applied Research

\section{Fair Housing and the Analysis of Impediments}

Discrimination in the sale and rental of housing has been an ignominy in the US for most of its history. The first significant step to stamp out discrimination in US housing markets occurred with the passage of the Fair Housing Act of 1968. The Act prohibited discrimination at any point in the sale or rental of housing on the basis of race, color, religion, sex, and national origin. Under the Act, the US Department of Housing and Urban Development (HUD) was designated as the federal agency to administer programs related to fair housing. HUD was authorized to affirmatively further fair housing in all of its programs and funded activities. Since that point in time, the Act has been amended and HUD has muddled through the process of promulgating rules and implementing fair housing policy (Yinger, 1999; Connerly, 2006; Schill, 2007; Squires, 2008; Silverman \& Patterson, 2012). For the most part, government's commitment to eradicate discrimination in housing markets at the federal, state, and local levels has waxed and waned since the adoption of the Act (Tisdale, 1999; Sidney, 2004; Lamb \& Wilk, 2009; Patterson \& Silverman, 2011; Seabrook et al., 2011; Wilk et al., 2011). Inconsistent enforcement of the Act has been compounded by the imprecise definition of its goal to affirmatively further fair housing.

This article focuses on a specific component of HUD's strategy to implement fair housing policy, its requirement for local jurisdictions that receive community development block grant
(CDBG) dollars to prepare an analysis of impediments to fair housing choice (AI) report. HUD recommends that jurisdictions prepare a new AI every three to five years (US Department of Housing and Urban Development, 1996). The purpose of AI reports is to identify impediments to fair housing and develop strategies to reduce them. In principle, AI reports should be proactive and guided by the Fair Housing Act's goal of affirmatively furthering fair housing.

We focused our analysis on the AI reporting process because it involves two critical steps in the fair housing enforcement process. First, the AI report sets the parameters for local fair housing enforcement. Local jurisdictions identify impediments to fair housing in their AI reports and develop action plans to reduce them. Second, AI reports are part of HUD's annual certification process for CDBG grantees. Each year, jurisdictions receiving CDBG funds must certify that they are meeting HUD's requirements for affirmatively forwarding fair housing, which include preparing an AI report and having it on file. Local jurisdictions are not required to submit their AI reports to HUD as part of the certification process. HUD generally accepts grantees' annual certifications of affirmatively furthering fair housing, and does not initiate further review unless third party complaints produce evidence that suggest otherwise. Although these two steps in the fair housing enforcement process are important, they have been criticized for lacking specificity and mandating that local jurisdictions submit AI reports to HUD for review and approval (US Government Accountability 
Office, 2010).

There have also been shortcomings in other aspects of the implementation of fair housing policy. One of the most notable shortcomings of the AI reporting process is that there has been insufficient monitoring and evaluation of local jurisdictions' implementation of action plans to reduce impediments to fair housing. Historically, following the preparation of an AI report by a local jurisdiction, HUD conducts no review of performance. The local jurisdiction simply certifies that the AI exists on an annual basis. The lack of monitoring and evaluation has hampered HUD's ability to enforce fair housing policy, and this has been compounded by the dearth of clearly articulated benchmarks and timetables for the implementation of local jurisdictions' action plans. In essence, AI reports identify impediments to fair housing and develop action plans to address them, but there is no formal process in place to ensure they will be implemented. Literally and figuratively, they are paper tigers.

The lack of provisions for monitoring and evaluating local jurisdictions' implementation of action plans from their AI reports had not gone unnoticed by HUD. One recent attempt to address this problem has entailed stepped up efforts by nonprofit fair housing organizations to evaluate the performance of local jurisdictions on their AI action plans. In the case we examined for this article, a local nonprofit fair housing organization received funding from HUD to perform such an evaluation and make recommendations to improve the AI reporting process. We received a small grant from the American Sociological Association's Sydney S. Spivack Program in Applied Social Research and Social Policy to augment this evaluation. In this article, we discuss the rationale for this project, its design, our findings, and the role of university-community collaborations in continuing this research.

\section{Talking the Fair Housing Act's Talk}

Symbolically, the Fair Housing Act of 1968 represented a monumental shift in US housing policy. Before the Act, individuals facing discrimination in housing markets had practically no legal recourse. After the Act's passage, individuals could file complaints with HUD and had standing to sue when they believed they were discriminated against in their search for housing. However, this statutory milestone was narrowly constructed and focused wholly on providing remedies to individuals who experienced discrimination. The Act did not provide remedies for structural forms of discrimination faced by ascribed groups or classes in society. Instead, the burden of demonstrating that acts of discrimination had occurred was firmly placed on those who had been victimized.

The Act was narrowly constructed in a number of other ways (Landis \& McClure, 2010; Yinger, 1999). The Act did not apply to a large proportion of properties available for rent or purchase. The law did not apply to rental properties with four or fewer units, and it did not apply to home sales unless real estate agents were used. As a result, many renters and homebuyers remained unprotected from housing discrimination. When the Act did apply, mechanisms for fair housing enforcement were extremely weak. HUD had no enforcement powers when fair housing violations were identified. Instead, HUD filled a conciliation role where it could notify the US Department of Justice (DOJ) about suspected violations of law in extreme cases of discrimination. In response, the DOJ would take action on a small number of highly egregious cases. Fair housing enforce- ment was further hampered since individuals only had 180 days to file a lawsuit, they were responsible for all court costs and attorneys' fees (unless a court waived them due to economic hardship), and punitive damages were capped at $\$ 1000$.

The Fair Housing Act of 1968 remained untouched for twenty years. After decades of advocacy for strengthening the Act, a small number of key amendments were finally adopted. The 1988 amendments to the Act expanded protections to those facing housing discrimination based on disability and family status. The amendments also gave HUD greater latitude in the fair housing enforcement process. HUD was granted power to hold administrative hearings and impose fines and damages for fair housing violations. The time limit for individuals to file civil suits was extended from 180 days to 2 years, and caps on damages that could be awarded to complainants were significantly increased ${ }^{1}$.

Although the 1988 amendments to the Fair Housing Act represented progress, it was hardly a watershed moment. Since 1988, there have been few advances in federal fair housing policy. It has been over 25 years since fair housing protections were extended to additional groups or classes. There is still no federal fair housing protection based on marital status, sources of income, sexual orientation, gender identification, political affiliation, Housing Choice Voucher (HCV) status, or other characteristics. The Act remains focused on individual complaints and lacks remedies for structural forms of discrimination. In addition, rental properties with four or fewer units and home sales where real estate agents are not used remain exempt from the Act.

\section{Not Quite Walking the Fair Housing Walk}

The evolution of local fair housing policy implementation has followed a parallel path to the development of federal fair housing law. The 1988 amendments to the Fair Housing Act included language requiring HUD to establish fair housing review criteria for jurisdictions receiving CDBG funds. Jurisdictions that met these criteria would receive certification from HUD that they were affirmatively furthering fair housing. In order to establish that these criteria had been met, HUD promulgated rules requiring jurisdictions to: produce AI reports, take action to eliminate any identified impediments to fair housing, and maintain records of their efforts to affirmatively further fair housing. Initially, the policies surrounding the AI process were somewhat vague and inconsistently enforced.

In order to create more consistency in the AI process, HUD produced its Fair Housing Planning Guide in 1996, which provided jurisdictions with instructions for developing their AI reports and implementing their action plans (US Department of Housing and Urban Development, 1996). This guide recommends that jurisdictions complete a new AI report every three to five years (consistent with their CDBG consolidated planning cycle). However, timing for preparing new AI reports is left to the discretion of local jurisdictions. The guide also suggested that jurisdictions identify milestones, timetables and measure-

\footnotetext{
${ }^{1}$ The 1988 Amendment to the Fair Housing Act removed the \$1000 cap on punitive damages, allowed for complainants to recover court costs and attorneys' fees, and placed no limits on compensatory awards from the courts. Under the amendments to the Act, cases heard by administrative law judges could receive a civil penalty of up to $\$ 10,000$ for the first discriminatory practice, up to $\$ 25,000$ if the respondent has committed another violation within the prior five years, or up to $\$ 50,000$ if the respondent committed two or more violations within the prior seven years.
} 
able results to be achieved in their action plans. Yet, the identification of these metrics is not mandatory. Since the promulgation of rules related to AI reports, HUD has continued to hold the position that jurisdictions maintain records of actions taken to affirmatively further fair housing and report on their implementation of AI action plans (US Department of Housing and Urban Development, 2004; US Department of Housing and Urban Development, 2007). However, no clear enforcement mechanism exists to prompt jurisdictions to do so.

Compliance with HUD's AI reporting rules have been a source of concern since their inception. In 2009, HUD completed and internal Analysis of Impediments Study which found that many AIs were outdated, lacking detail and subject to limited oversight by the agency (US General Accountability Office, 2010). In its own independent study, the US Government Accountability Office (GAO) (2010) reached similar conclusions. The GAO conducted a study using a national sample of 411 jurisdictions and concluded that: $29 \%$ of all AIs were outdated, there were broad discrepancies in the content and completeness of reports, AI authorship and the types of impediments identified varied widely, and most reports lacked timeframes for implementing recommendations. The GAO study also found that the large proportion of outdated and inconstantly prepared AI reports could be partly attributed to HUDs limited regulatory requirements, oversight and enforcement. According to the GAO, HUD did not have well defined standards in place for the formatting of AI reports and timely AI reporting, and jurisdictions were not required to submit the full text of AI reports to HUD. The GAO concluded that HUD lacked the capacity to provide jurisdictions with technical support and other assistance necessary to assure that AIs serve as an effective planning tool.

Following the issuance of the GAO's findings in 2010, HUD began to take steps to increase the level of scrutiny given to AI reports and increase efforts to provide local jurisdictions with training and assistance in the AI process. However, core concerns identified in the GAO report related to timeliness of AI reporting, the content of AI reports, and HUD's capacity remained unaddressed.

\section{The Evaluation}

Our analysis adds an additional perspective to earlier critiques of the AI reporting process. We focus specifically on evaluating the implementation of the AI action plans generated through this process. This focus was adopted in response to concerns raised about the consistency of monitoring and reporting related to AI implementation. These concerns were raised in the GAO's (2010) study of AIs and echoed in our interactions with local fair housing advocacy organizations and housing officials.

Our focus on evaluating the implementation of AI action plans also grew out of a unique collaboration on an applied research project. In 2011, Housing Opportunities Made Equal of Buffalo (HOME) $)^{2}$ was awarded a Fair Housing Initiatives Program (FHIP) ${ }^{3}$ grant from HUD. One activity HOME received funding to engage in under the grant was an evaluation of local jurisdictions' performance on AI action plans. HOME planned

${ }^{2} \mathrm{HOME}$ is a not-for-profit, membership based, civil rights organization in western New York. It was founded in 1963. Its mission is to promote the value of diversity and to ensure the people of western New York an equal opportunity to live in the housing and communities of their choice through education, advocacy, enforcement of fair housing laws, and the creation of housing opportunities. to evaluate AI performance for four jurisdictions in the Buffalo-Niagara Falls metropolitan area over a three year period. The largest municipality that HOME planned to evaluate was the City of Buffalo, NY. Buffalo is the second largest city in the State of New York. Its 2010 population was 261,310 (www.census.gov). The city's population was 38.6\% black and 10.5\% Latino (www.census.gov). According to the US2010 progject at Brown University (http://www.s4.brown.edu/us2010), in 2010 Buffalo had a white-black dissimilarity index of $65.8^{4}$. This indicated that there was a high degree of segregation between whites and blacks in the city, where $65.8 \%$ of blacks would have to move in order for the city to be racially integrated. In 2010, the city had a white-Latino dissimilarity index of 43.4. This indicated that a moderate degree of segregation existed between whites and Latinos, where $43.4 \%$ of Latinos would have to move in order for the city to be ethnically integrated.

We were invited to collaborate with HOME on the evaluation of the City of Buffalo's 2004 AI report. We received a small grant from the American Sociological Association's Sydney S. Spivack Program in Applied Social Research and Social Policy to augment HOME's evaluation and to develop this article as a companion piece to this work. During the spring and summer of 2012 we collaborated with HOME to analyze the City's 2004 AI report, collect data on the implementation of its action plan, and draft a memorandum to HUD summarizing the findings from the evaluation.

The evaluation was based on an examination of the AI action plan. Data were collected related to each item in the action plan and efforts were made to determine if the City had taken proactive steps to reduce identified impediments to fair housing. Data were collected from municipal documents, HOME records, HUD, and other sources. These included the City's past and current CDBG consolidated plans, city ordinances and land-use policies, and related records from Erie County, $\mathrm{NY}^{5}$. In addition to public records and archival materials, data were collected through meetings held with officials from the City's Office of Strategic Planning, the City's Fair Housing Officer, and the Director of the City's Rental Registration program. During these meetings, the action items from the 2004 AI were reviewed and the individuals who we met with provided written and verbal responses to questions concerning steps the City had taken to reduce identified impediments.

The data were analyzed by quantifying the number of action items that the City had taken steps to address and through a qualitative assessment of how effective the City's efforts were at reducing impediments to fair housing. For each action item,

\footnotetext{
${ }^{3}$ The Fair Housing Initiatives Program (FHIP) was established as a component of the Housing and Community Development Act of 1987 (amended in 1992). Under the program, grants are awarded to nonprofit housing organizations on a competitive basis. FHIP organizations undertake activities to enhance compliance with fair housing law. These activities include education, monitoring, routing complaints to other agencies for investigation, and fair housing compliance programs.

${ }^{4}$ The dissimilarity index measures whether one particular group is distributed across census tracts in a geographic area in the same way as another group. A high value indicates that the two groups tend to live in different tracts. Dissimilarity indexes range from 0 to 100 . A value of 60 (or above) is considered very high. It means that $60 \%$ (or more) of the members of one group would need to move to a different tract in order for the two groups to be equally distributed. Values of 40 or 50 are usually considered to reflect a moderate level of segregation, and values of 30 or below are considered to be fairly low.

${ }^{5}$ Erie County, NY is the county where the city of Buffalo is located.
} 
we also identified the degree to which tools for reducing an impediment fell within the City's locus of control. The results from this analysis are summarized in the next section of this article.

\section{Results}

\section{Fair Housing Complaints}

It is estimated that over 4 million instances of housing discrimination occur annually in the US, but less than 1 percent of them are reported to HUD or FHAP ${ }^{6}$ agencies (Silverman \& Patterson, 2012). This discrepancy is attributed to a number of factors. Victims of housing discrimination lack information about how to report instances, and they perceive the complaint process as cumbersome and ineffective. These perceptions are aggravated by the limited capacity of local housing agencies and advocacy groups to pursue complaints and lax enforcement of fair housing laws. Also, records of fair housing complaints are often incomplete and kept in an inconsistent manner over time. Many of these shortcomings can be observed at the local level.

For example, Buffalo's 2004 AI report indicated that HOME received 884 housing discrimination complaints between 1999 and 2003 (City of Buffalo, 2004). Those complaints were based on: race/color (35\%), familial status (30\%), disability (19\%), and source of income (13\%). The 2004 AI report also indicated that HUD pursued 57 housing discrimination cases in Buffalo between 1999 and 2003. Those cases were based on: race/color (40\%), familial status (28\%), and disability (23\%). At the time of this study, HOME no longer maintained complete internal records of discrimination complaints. This was due to staff turnover and reduced funds for fair housing enforcement. HOME staff also indicated that the intake of complaints was hampered by reductions in staffing, and they speculated that there were fewer complaints received than in the past due to this predicament. Consequently, discrimination complaints were pursued when available staff became aware of them and were able to document them, and when victims of discrimination were persistent in reporting. A smaller subset of complaints received by HOME were well enough documented and substantial enough to forward to HUD or FHAP agencies for action.

HOME, the City of Buffalo, and other local agencies were unable to provide complaint intake records for the years following Buffalo's 2004 AI report. When these records were requested for this analysis, respective agencies indicated that they were not maintained, could not be located, or were unavailable for some other reason. However, HUD and FHAP discrimination case records for Buffalo were available from 2004 to 2012. These records came from HUD's Title VIII Automated Paperless Office Tracking System (TEAPOTS) database. These data are summarized in Tables $\mathbf{1}$ and $\mathbf{2}$. They include annual counts of HUD and FHAP housing discrimination cases processed, and the basis for discrimination in those cases. These data also report the outcomes of housing discrimination cases. Although these data only reflect instances of housing discrimination that were included in HUD and FHAP case files, they provide insights into the scope of discrimination occurring in Buffalo during the implementation of the action plan from the 2004 AI report.

Table 1 summarizes TEAPOTS data for Buffalo between 2004 and 2012. The volume of cases processed by HUD and FHAP agencies during this period was comparable to the volume identified in the City's 2004 AI report. Moreover, the basis for discrimination in cases processed between 2004 and 2012 were similar to the instances of discrimination discussed in the

Table 1.

2004-2012 HUD and FHAP Processed Housing Discrimination Cases for Buffalo, NY ${ }^{1}$.

\begin{tabular}{ccccccccccc}
\hline Year & $\begin{array}{c}\text { Percent } \\
\text { Race }\end{array}$ & $\begin{array}{c}\text { Percent } \\
\text { Color }\end{array}$ & $\begin{array}{c}\text { Percent } \\
\text { National Origin }\end{array}$ & $\begin{array}{c}\text { Percent National } \\
\text { Origin-Hispanic }{ }^{2}\end{array}$ & $\begin{array}{c}\text { Percent } \\
\text { Religion }\end{array}$ & Percent Sex & $\begin{array}{c}\text { Percent } \\
\text { Disability }\end{array}$ & $\begin{array}{c}\text { Percent } \\
\text { Familial Status }\end{array}$ & $\begin{array}{c}\text { Percent } \\
\text { Retaliation }\end{array}$ & $\begin{array}{c}\text { Total Cases } \\
\text { Processed }\end{array}$ \\
\hline 2004 & 38.1 & 9.5 & 4.8 & 4.8 & 4.8 & 28.6 & 28.6 & 42.9 & 9.5 & 21 \\
2005 & 50.0 & - & 11.5 & 3.8 & 3.8 & 7.7 & 26.9 & 26.9 & 3.8 & 26 \\
2006 & 50.0 & 11.1 & - & - & - & 27.8 & 27.8 & 33.3 & 5.6 & 18 \\
2007 & 58.8 & - & 17.6 & - & 5.9 & 11.8 & 47.1 & 5.9 & 11.8 & 17 \\
2008 & 33.3 & 6.7 & 6.7 & - & - & 26.7 & 40.0 & 40.0 & - & 15 \\
2009 & 50.0 & 23.1 & 15.4 & 7.7 & - & 7.7 & 34.6 & 30.8 & - & 26 \\
2010 & 56.0 & 8.0 & 12.0 & - & 8.0 & 8.0 & 40.0 & 24.0 & 8.0 & 25 \\
2011 & 36.4 & 9.1 & 9.1 & - & - & 54.5 & 9.1 & 45.5 & 9.1 & 11 \\
2012 & 23.1 & 7.7 & 23.1 & 23.1 & - & 30.8 & 38.5 & 53.8 & 15.4 & 13 \\
$2004-12$ & 45.9 & 8.7 & 11.0 & 4.1 & 2.9 & 19.2 & 33.1 & 32.0 & 6.4 & 172 \\
\hline
\end{tabular}

Note: Source: US Department of Housing and Urban Development (HUD). Fair Housing and Equal Opportunity Office, Title VIII Automated Paperless Office Tracking System (TEAPOTS) ${ }^{1}$ Cases may have more than one basis for discrimination so the total percent across cases for a given year may be greater than $100 \%{ }^{2}$ National Origin-Hispanic is a subset of National Origin.

\footnotetext{
${ }^{6}$ The Fair Housing Assistance Program (FHAP) was established in 1979. Under the program, grants are awarded annually on a noncompetitive basis to state and local fair housing agencies. FHAP agencies are referred complaints from HUD and other organizations and charged with the task of investigating instances of housing discrimination in their jurisdictions. Based on those investigations, complaints can be dismissed, conciliated/settled, or referred to the US Department of Justice (DOJ) or courts for litigation.
} 
Table 2.

2004-2013 HUD and FHAP Processed Housing Discrimination Case Outcomes for Buffalo, NY.

\begin{tabular}{|c|c|c|c|c|c|c|c|}
\hline Year & $\begin{array}{c}\text { Percent } \\
\text { Administrative Closure }^{1}\end{array}$ & $\begin{array}{c}\text { Percent } \\
\text { Cause (FHAP) }{ }^{2}\end{array}$ & $\begin{array}{c}\text { Percent } \\
\text { Charged (HUD) }{ }^{3}\end{array}$ & $\begin{array}{c}\text { Percent } \\
\text { Conciliated/Settled }^{4}\end{array}$ & $\begin{array}{l}\text { Percent } \\
\text { No Cause }^{5}\end{array}$ & $\begin{array}{l}\text { Percent } \\
\text { Open }^{6}\end{array}$ & $\begin{array}{c}\text { Total Cases } \\
\text { Processed }\end{array}$ \\
\hline 2004 & - & 9.5 & 4.8 & 38.1 & 47.6 & - & 21.0 \\
\hline 2005 & 7.7 & 3.8 & - & 50.0 & 38.5 & - & 26.0 \\
\hline 2006 & 5.6 & 11.1 & - & 16.7 & 66.7 & - & 18.0 \\
\hline 2007 & - & 17.6 & - & 11.8 & 70.6 & - & 17.0 \\
\hline 2008 & 13.3 & - & - & 26.7 & 60.0 & - & 15.0 \\
\hline 2009 & 3.8 & 19.2 & 3.8 & 15.4 & 57.7 & - & 26.0 \\
\hline 2010 & 12.0 & 8.0 & - & 20.0 & 60.0 & - & 25.0 \\
\hline 2011 & 9.1 & 27.3 & - & 18.2 & 45.5 & - & 11.0 \\
\hline 2012 & - & 7.7 & - & 7.7 & 46.2 & 38.5 & 13.0 \\
\hline 2004-12 & 5.8 & 11.0 & 1.2 & 24.4 & 54.7 & 2.9 & 172.0 \\
\hline
\end{tabular}

Note: Source: US Department of Housing and Urban Development (HUD), Fair Housing and Equal Opportunity Office, Title VIII Automated Paperless Office Tracking System (TEAPOTS). ${ }^{1}$ HUD and FHAP agencies administratively close complaints when the complainant withdraws the complaint, fails to cooperate, or can no longer be located. Agencies also close complaints when, after accepting the complaint, it is determined that they lack jurisdiction. ${ }^{2} \mathrm{~A}$ reasonable cause determination is issued when an FHAP agency has completed a full investigation and found that there is reasonable cause to believe that a discriminatory housing practice has occurred. ${ }^{3} \mathrm{HUD}$ issues a charge of discrimination when it has completed a full investigation and found that there is reasonable cause to believe that a discriminatory housing practice has occurred. ${ }^{4} \mathrm{~A}$ complainant and respondent have entered into a conciliation agreement or private settlement. ${ }^{5} \mathrm{HUD}$ and/or FHAP agencies found no reasonable cause to believe that a discriminatory housing practice has occurred. ${ }^{6}$ Cases open and still under investigation.

2004 AI report. The three most prevalent forms of housing discrimination in Buffalo between 2004 and 2012 were based on race $(45.9 \%)$, disability (33.1\%), and familial status (32\%). Despite constraints that local government and fair housing organizations faced related to the intake of discrimination complaints, patterns of discrimination remained relatively stable in the city during the implementation of the action plan for the 2004 AI report.

Table 2 adds to our understanding of fair housing implementation in Buffalo. This table summarizes outcomes of discrimination cases originating in the city between 2004 and 2012. These data are important because they provide insights into the effectiveness of the intake and referral process for fair housing complaints. In over half (54.7\%) of the cases processed by HUD and FHAP agencies, it was determined that there was no reasonable cause that a discriminatory housing practice had occurred. This suggests that little vetting took place at the intake level when complaints were received by local government and fair housing organizations. Instead, complaints were simply forwarded to HUD and FHAP agencies. After cases determined to have no cause for discrimination complaints were removed, the vast majority of the remaining cases processed by HUD and FHAP agencies resulted in a conciliation, settlement, or criminal charges being filed. Despite the relatively low volume of cases processed in Buffalo, about one-third (36.6\%) resulted in a favorable outcome for victims of housing discrimination. Given the obstacles that victims face in filing a complaint and receiving assistance from local agencies and organizations, the case outcomes suggest that housing discrimination remained a salient issue in Buffalo during the implementation of the City's 2004 AI report.

\section{Implementation of the AI Action Plan}

The City of Buffalo identified 32 distinct impediments to fair housing in its 2004 AI report. The report included action items to address those impediments. Table 3 summarizes the impediments that were identified in the report. They are subdivided into four broad categories following the methodology used by the GAO (2010) in its analysis of AI reports. In addition to providing counts of the types of impediments identified in the City's 2004 AI report, we further subdivided impediments along two dimensions: the City's locus of control to take action on identified impediments to fair housing, and the City's performance in reducing impediments to fair housing since the report was adopted. Adding these two dimensions to the analysis enhances our understanding of the AI implementation process. Considering the City's locus of control allows us to assess the degree to which the City had autonomy when taking action on identified impediments to fair housing. We hypothesized that impediments that were within the City's locus of control would be more likely to be reduced. Table 3 provides some support for this hypothesis. Yet, the City's performance on reducing impediments to fair housing remained low for the preponderance of the action items examined.

The low levels of performance on reducing impediments to fair housing are attributed to a number of factors. Many are linked to issues identified by the GAO (2010) in its analysis of AIs. These factors include the limited capacity and technical expertise of local government, overly broad definitions of identified impediments, ambiguity in action plans, poorly communicated parameters for monitoring progress on reducing impediments, and limited technical support from HUD in the AI process. The City of Buffalo was further hampered in its efforts 
Table 3.

Type of Impediments Identified in the 2004 Buffalo AI Report with Summary Evaluation of City’s Locus of Control \& Performance.

\begin{tabular}{|c|c|c|c|c|c|c|c|}
\hline \multirow{2}{*}{ Impediments } & \multirow{2}{*}{ Number Identified } & \multicolumn{3}{|c|}{ City's Locus of Control } & \multicolumn{3}{|c|}{ City’s Performance } \\
\hline & & High & Medium & Low & High & Medium & Low \\
\hline Zoning, Code Enforcement, Local Ordinances and Policies & 7 & $100 \%$ & - & - & $14 \%$ & - & $86 \%$ \\
\hline $\begin{array}{l}\text { Neighborhood Revitalization \& Affordable/Accessible } \\
\text { Housing Development }\end{array}$ & 7 & $100 \%$ & - & - & - & $14 \%$ & $86 \%$ \\
\hline Lending \& Real Estate & 12 & $8 \%$ & $50 \%$ & $42 \%$ & $8 \%$ & - & $92 \%$ \\
\hline Informational \& Educational programs & 6 & $67 \%$ & $33 \%$ & - & $17 \%$ & - & $83 \%$ \\
\hline Total & 32 & $38 \%$ & $47 \%$ & $15 \%$ & $9 \%$ & $3 \%$ & $88 \%$ \\
\hline
\end{tabular}

to implement its AI action plan due to fiscal constraints, declining CDBG allocations, and turnover in key staff positions. Since the adoption of it AI report in 2004, the City had replaced key staff in its Office of Strategic Planning (OSP) and restructured several positions. This led to a loss of institutional memory concerning the implementation of the AI report. This problem became apparent in our discussions with OSP staff during our data collection. For example, at an initial meeting a senior staff member indicated that he was unaware of the City's AI report before we contacted him about our evaluation. This staff person was the third to occupy his position since the 2004 AI report was adopted. Turnover in staff had negative implications for continuity in the implementation of the City's fair housing action plan.

\section{Buffalo's Fair Housing Ordinance}

Problems with staffing and capacity were manifested in a variety of other ways that negatively impacted the implementation of the City's fair housing action plan. One of the more illustrative examples of how these constraints affected the City's ability to reduce impediments to fair housing involved its fair housing ordinance. In response to the 2004 AI report, the City of Buffalo adopted a fair housing ordinance. It was adopted in 2006 and extended fair housing protection in the city to classes of individuals unprotected by federal law, such as individuals experiencing housing discrimination based on their source of income. The ordinance included a framework for filing complaints, assessing fines for local fair housing violations, and other enforcement mechanisms. The ordinance identified a Fair Housing Officer as the individual responsible for the implementation of the new law. This was a new position to be appointed by the Mayor. One key provision in the ordinance was the establishment of fines and other civil penalties for violating local fair housing laws. Another key provision of the ordinance was the requirement for the City to prepare an annual fair housing report. This requirement included the following:

The Fair Housing Officer shall prepare an annual report detailing the work performed including a statistical analysis of the caseload, a summary of dispositions of complaints filed and/or referred to housing agencies, and recommendations regarding fair housing practices. This report shall be submitted to the Mayor and filed with the City Clerk no later than March 1st of each year. Copies shall also be sent to the Commissioner of the New York State Division of Human Rights, the Attorney General of the State of New York, and the Secretary of the United
States Department of Housing and Urban Development ( $§ 154$ - 21, Code of the City of Buffalo).

The City's fair housing ordinance contained strong language and provisions for expanded fair housing protections. This gave it a high degree of symbolic value. Still, it has been a failure on substantive grounds due to the lack of implementation. For example, the Fair Housing Officer's position that is identified in the ordinance has been understaffed or vacant since the law was adopted. The lack of consistent staffing has led to a lapse in enforcement of the ordinance. No records of fines, civil penalties, or other enforcement actions have been maintained since the adoption of the ordinance. Moreover, the City of Buffalo has never prepared an annual report on the work performed under the law. This is particularly indicting, since this indicates that the City has been out of compliance with its own fair housing ordinance since its adoption in 2006.

Lax implementation of the City of Buffalo's fair housing ordinance can be viewed as a microcosm of fair housing policy implementation nationally (US General Accountability Office, 2010; Silverman \& Patterson, 2012). Chronic underfunding of fair housing programs, limited staff capacity and technical support, and inconsistent monitoring by state and federal fair housing agencies have contributed to scant implementation of fair housing laws at the local, state and federal levels. Many of the issues that affect fair housing enforcement are outside of local governments' locus of control. Nevertheless, these constraints frame the scope of local enforcement activities. This is clearly reflected in our findings from the evaluation of the implementation of Buffalo’s 2004 AI report.

\section{The Memorandum to HUD}

In August 2012, HOME submitted a memorandum to HUD summarizing the findings from its evaluation of the implementation of the City of Buffalo's 2004 AI report. The memorandum discussed the impediments identified in the City's AI report and progress made in reducing them. Overall, the memorandum indicated that the City made little progress in reducing impediments to fair housing between 2004 and 2012. Largely, this was an outgrowth of lax implementation and a dearth of municipal resources allocated to affirmatively further fair housing. These conditions were reflected in the following statement from the memorandum:

The rate of progress in implementing the City's action items appears to have been slowed by inconsistent staffing of key positions related to fair housing and limited civil 
service protection for individuals assigned to implement and enforce fair housing policies... There has also been limited financial support for fair housing activities and little evidence of systematic code enforcement, demolition, and development of other targeted programs that would improve housing choices, particularly in areas with concentrated minority populations.

The memorandum went on to discuss how implementation of action items from the 2004 AI report was varied based on the degree to which remedies to impediments were within the City's locus of control. The following excerpt from the memorandum highlights this distinction:

The City appeared to make the most progress on action items within its locus of control. This was reflected in the adoption of a local fair housing ordinance in 2006 and other areas. However, there was less progress in the implementation of this new policy and other areas related to zoning, accommodations for the disabled, and reforming restrictive use permit policies for nonprofit service providers.

Ironically, the City's fair housing ordinance was identified as an example of noticeable progress in reducing impediments to fair housing in the memorandum. However, as noted above, resource constraints have hampered the implementation of the fair housing ordinance since its adoption. In contrast to the modest progress achieved with the adoption of the fair housing ordinance, the memorandum went on to conclude that the city had less success in reducing impediments outside of its immediate locus of control. For example, the memorandum concluded that, "the City made no progress in addressing impediments associated with the [Buffalo Niagara Association of Realtors] BNAR, and there was little evidence of outreach to the [Niagara Frontier Transportation Authority] NFTA.” The memorandum went on to conclude that although the City has less influence over external entities, "City officials have a bully pulpit to advocate for positive change and there is little evidence that they have done so." Even when opportunities to take action merely involved initiating dialogue with an external organization, the City failed to take steps to affirmatively further fair housing. In part, this can be attributed to resource constraints, but it also seems to reflect a lack of political will to take action on fair housing.

The memorandum partially attributed the lack of performance in reducing impediments to fair housing to the lackluster oversight of the AI process by HUD. Specifically, the lack of requirements for the City to identify outcome measures and benchmarks in its 2004 AI was cited as problematic. The memorandum suggested that HUD promulgate more specific rules and guidelines for monitoring and reporting outcomes in order to address this problem. In the absence of outcome measures and benchmarks, the City essentially deferred from taking action on fair housing and routinely kicked the can down the road. One manifestation of the tendency to defer from taking action was the City's repeated claim that plans were in the works for future activities that tied into fair housing. Throughout the evaluation city officials were asked about performance on past action items identified in the AI report. They routinely responded that action items would be addressed by initiatives that were being planned for the future. For example, on several occasions city officials suggested that a lack of action to remove impedi- ments would be addressed when the City's new land use ordinances, referred to as the "Green Code", were adopted. Concerns were raised about this in the memorandum:

There is cause for concern about the extent to which the Green Code will serve as a vehicle to affirmatively further fair housing, since there is little detail available about it and specific recommendations related to fair housing were not identified. For example, there has been no discussion of an inclusionary zoning ordinance, set asides for affordable housing, or other mechanisms to affirmatively further fair housing in the current dialogue surrounding the Green Code.

At the time of this writing a draft version of the Green Code has not been made available to the public for discussion. A draft version was originally planned for release by the City in September of 2012, but it was delayed for undisclosed reasons.

After HOME submitted its memorandum to HUD, the City of Buffalo provided no official response to the issues identified in the evaluation. Instead, the City indicated that it planned to prepare a new AI report with its 2013-2018 CDBG Consolidated Plan. In October of 2012, a private consultant was hired by the City to conduct a new AI report. This came on the heels of HOME's evaluation which indicated that the City's past performance on its 2004 AI was relatively poor. It is possible that HOME's evaluation of the City's performance on the action plan sped up the initiation of a new AI study. The City may have also been prompted to revisit its AI due to growing pressure from HUD and other agencies, like the GAO, to improve fair housing monitoring and reporting efforts.

\section{Recommendations for Action}

This analysis helps to refine recommendations to improve the AI reporting process and augment efforts of local jurisdictions to affirmatively further fair housing. In 2010, the GAO (2010) offered specific recommendations to improve the AI reporting process. One GAO recommendation was for HUD to require jurisdictions to include timeframes for the implementation of their fair housing action plans in their AI reports. These timeframes would serve as foundations for establishing benchmarks and measuring jurisdictions' performance on reducing identified impediments to fair housing. Another GAO recommendation was to mandate that jurisdictions update their AIs at regular intervals, rather than simply leave the timing of AI updates to each jurisdiction's discretion. The GAO further recommended that HUD establish a specific format and identify required content for jurisdictions to include in their AI reports. Finally, the GAO recommended that HUD require all jurisdictions to submit their AI reports to the agency for review and approval. These recommendations were made with the goal of ensuring that AIs serve as an effective planning tool for the affirmative furthering of fair housing policy.

Our experience with the evaluation of Buffalo's 2004 AI suggests that additional engagement with local jurisdictions would augment to benefits of adopting recommendations like the ones the GAO made in 2010. In particular, we believe that HUD should put even greater emphasis on the evaluation of outcomes in the AI process. The focus on evaluation should be tied to measurable outcomes, and mandates for local jurisdictions to document them throughout the AI implementation process. In order to implement ongoing evaluation, HUD should 
require local jurisdictions to include an evaluation plan in their AI reports. In addition to the development of measurable outcomes and evaluation plans, we believe that HUD should require AI reports to focus on identifying impediments that are within a local jurisdiction's locus of control. This would allow for local fair housing action plans to be more closely aligned with the deployment of CDBG and other funds available to local jurisdictions.

Finally, our experience with the evaluation of Buffalo's 2004 AI highlights the value of conducting an independent assessment of a jurisdiction's performance. HUD included funding for HOME's evaluation of the City's AI in the organization's 2011 FHIP grant. HUD's support of the evaluation of AI outcomes in Buffalo made fair housing enforcement a more salient issue to the City. The presence of an independent evaluation team was further enhanced by the university-community collaboration that was forged between HOME and researchers from the University at Buffalo. In part, HUD's support of outside evaluation and the university-community partnership may have created a sense of urgency in the City and prompted it to be more attentive to fair housing planning. The presence of independent evaluators appeared to have an effect similar to what Paul Light (1998) described as watchful eye policies adopted to improve program performance in government. We believe that HUD should institutionalize the role of independent evaluators into the AI process in order to make local fair housing planning and implementation more transparent.

Ongoing evaluation of fair housing performance will increase the relevance of AI reports as planning tools. An increased emphasis on evaluation will also create incentives for local government to identify impediments to fair housing that are measurable and within their locus of control. There are several potential benefits of generating data that can be used for evidence-based decisions about fair housing policy. These data can be used by those within government and outside organizations to educate the public and advocate for fair housing reforms. Evaluation data can also be used to identify best practices in fair housing policy. Moreover, local jurisdictions that can cite evaluation results in order to demonstrate progress in reducing impediments to fair housing can increase their chances of receiving federal and state funding in the future.

\section{Acknowledgements}

This research was funded by a Sydney S. Spivack Program in Applied Social Research and Social Policy, Community Action Research Initiative (CARI) grant, from the American Sociological Association. Additional funding for this research came from a Baldy Center Small Research Grant, from the Baldy Center for Law \& Social Policy at the University at Buffalo. We thank Scott Gehl, Jennifer Metzger Kimura, and Laurene Schrenk who collaborated on the evaluation of Buffalo's 2004 AI report.

\section{REFERENCES}

City of Buffalo (2004). Analysis of impediments to fair housing choice. Buffalo: City of Buffalo.
Connerly, C. E. (2006). Fair housing in the US and the UK. Housing Studies, 21, 343-360. doi:10.1080/02673030600585961

Lamb, C. M., \& Wilk, E. M. (2009). Presidents, bureaucracy, and housing discrimination policy: The fair housing acts of 1968 and 1988. Politics \& Policy, 37, 127-149. doi:10.1111/j.1747-1346.2008.00164.x

Landis, J. D., \& McClure, K. (2010). Rethinking federal housing policy. Journal of the American Planning Association, 76, 319-348. doi: $10.1080 / 01944363.2010 .484793$

Light, P. C. (1998). The tides of reform: Making government work, 1945-1995. New Haven: Yale University Press.

National Commission on Fair Housing and Equal Opportunity (2008). The future of fair housing: Report of the national commission on fair housing and equal opportunity. Washington DC: National Commission on Fair Housing and Equal Opportunity.

Patterson, K. L., \& Silverman, R. M. (2011). Public administrators, Nonprofit providers and elected officials perceptions of impediments to fair housing in the suburbs: An analysis of Erie County, New York. Housing Policy Debate, 21, 165-188. doi:10.1080/10511482.2010.534392

Schill, M. H. (2007). Implementing the federal fair housing Act: The adjucation of complaints. In J. Goering (Ed.), Fragile rights within cities: Government, housing and fairness (pp. 143-176). New York: Rowman \& Littlefield.

Seabrook, N. R., Lamb, C. M., \& Wilk, E. M. (2011). The federal courts and fair housing policy: A principle agent interpretation. In R. M. Silverman, \& K. L. Patterson (Eds.), Fair and affordable housing in the US: Trends, outcomes, future directions (pp. 41-66). Leiden: Brill. doi:10.1163/ej.9789004201446.i-346.18

Sidney, M. S. (2004). The Struggle for housing equality: Impact of fair housing and community reinvestment laws on local advocacy. Cityscape: A Journal of Policy Development and Research, 7, 135-163.

Silverman, R. M., \& Patterson, K. L. (2012). The four horsemen of the fair housing apocalypse: A critique of fair housing policy in the USA. Critical Sociology, 38, 123-140. doi:10.1177/0896920510396385

Squires, G. D. (2008). Prospects and pitfalls of fair housing enforcement efforts. In J. H. Carr, \& N. K. Kutty (Eds.), Segregation: The rising costs for America (pp. 305-323). New York: Routledge.

Tisdale, W. R. (1999). Fair housing strategies for the future: A balanced approach. Cityscape: A Journal of Policy, Development and Research, 4, 147-160.

US Department of Housing and Urban Development (1996). Fair housing planning guide. Washington DC: US Department of Housing and Urban Development, Office of Fair Housing and Equal Opportunity.

US Department of Housing and Urban Development (2004). Memorandum of September 2: Analysis of impediments to fair housing choice reissuance. Washington DC: US Department of Housing and Urban Development.

US Department of Housing and Urban Development (2007). Memorandum of February 9: Affirmatively furthering fair housing in the community development block grant program. Washington DC: US Department of Housing and Urban Development.

US Government Accountability Office (2010). Housing and community grants: HUD needs to enhance its requirements and oversight of jurisdictions' fair housing plans. Washington DC: US Government Accountability Office.

Wilk, E. M., Lamb, C. M., \& Seabrook, N. R. (2011). Intergovernmental enforcement of the fair housing Act: The fair housing assistance program. In R. M. Silverman, \& K. L. Patterson (Eds.), Fair and affordable housing in the US: Trends, outcomes, future directions (pp. 21-40). Leiden: Brill. doi:10.1163/ej.9789004201446.i-346.11

Yinger, J. (1999). Sustaining the fair housing Act. Cityscape: A Journal of Policy, Development and Research, 4, 93-106. 